\title{
Arterial stiffness in patients with COPD: the role of systemic inflammation and the effects of pulmonary rehabilitation
}

\author{
Lowie E.G.W. Vanfleteren ${ }^{1,2}$, Martijn A. Spruit', Miriam T.J. Groenen', \\ Piet L.B. Bruijnzeel ${ }^{3}$, Ziad Taib³, Erica P.A. Rutten', Jos Op 't Roodt, \\ Marco A. Akkermans', Emiel F.M. Wouters ${ }^{1,2}$ and Frits M.E. Franssen ${ }^{1,2}$
}

Affiliations: ${ }^{1}$ Program Development Centre, CIRO+, Centre of Expertise for Chronic Organ Failure, Horn, ${ }^{2}$ Dept of Respiratory Medicine, Maastricht University Medical Centre (MUMC+), Maastricht, and ${ }^{4}$ Dept of Internal Medicine, Maastricht University Medical Centre (MUMC+), Maastricht, The Netherlands. ${ }^{3}$ Translational Medicine Unit Respiratory, Inflammation and Autoimmunity, AstraZeneca, Mölndal, Sweden.

Correspondence: L.E.G.W. Vanfleteren, Centre of Expertise for Chronic Organ Failure, PO Box 4080, 6080 AB Haelen, The Netherlands. E-mail: lowievanfleterendaciro-horn.nl

ABSTRACT Clear evidence for an association between systemic inflammation and increased arterial stiffness in patients with chronic obstructive pulmonary disease (COPD) is lacking. Moreover, the effects of pulmonary rehabilitation on arterial stiffness are not well studied.

We aimed to 1) confirm increased arterial stiffness in COPD; 2) evaluate its correlates including systemic inflammation; and 3) study whether or not it is influenced by pulmonary rehabilitation.

Aortic pulse-wave velocity (APWV) was determined in 168 healthy volunteers, and APWV and inflammatory markers were determined in 162 COPD patients during baseline evaluation of a pulmonary rehabilitation programme. A complete post-pulmonary rehabilitation dataset was collected in 129 patients.

It was found that APWV was increased in COPD patients when compared with controls, blood pressure and age predicted baseline APWV, and systemic inflammatory markers were not independently related to APWV. Although baseline APWV was predictive for the change in APWV after pulmonary rehabilitation $(\mathrm{r}=-0.77)$, on average APWV did not change $\left(10.7 \pm 2.7\right.$ versus $\left.10.9 \pm 2.5 \mathrm{~m} \cdot \mathrm{s}^{-1} ; \mathrm{p}=0.339\right)$.

Arterial stiffness in COPD is not related to systemic inflammation and does not respond to state-of-theart pulmonary rehabilitation. These results emphasise the complexity of cardiovascular risk and its management in COPD.

@ERSpublications

Arterial stiffness in COPD is not related to systemic inflammation and does not respond to pulmonary rehabilitation http://ow.ly/tGW42

This article has supplementary material available from www.erj.ersjournals.com

Received: Sept 272013 | Accepted after revision: Nov 142013 | First published online: Dec 052013

Support statement: This study was supported by a research grant from AstraZeneca.

Conflict of interest: Disclosures can be found alongside the online version of this article at www.erj.ersjournals.com

Copyright @ERS 2014 


\section{Introduction}

Chronic obstructive pulmonary disease (COPD) is considered a complex and heterogeneous condition affecting multiple organ systems [1]. Indeed, cardiovascular disease is a major cause of death in COPD [2, 3]. Persistent low-grade systemic inflammation has been suggested as the pathophysiological link between both diseases [4], but evidence is lacking.

Aortic pulse wave velocity (APWV), considered to be the gold standard for measuring central arterial stiffness [5], is an independent predictor of cardiovascular events and mortality [6] and is increased in patients with COPD $[7,8]$. Arterial stiffness has been positively associated with levels of different systemic inflammatory markers in healthy individuals [9] and different patient populations [10, 11]. One COPD study showed weak correlations with interleukin (IL)-6 and soluble tumour necrosis factor receptor 1 (sTNFR1), but not with sTNFR2 [7].

Exercise-based pulmonary rehabilitation (PR) seems to have a beneficial effect on arterial stiffness in patients with COPD $[12,13]$. However, these results need to be confirmed in larger samples.

We sought to confirm increased arterial stiffness in patients with COPD referred for PR and to evaluate its determinants, including systemic inflammation. Moreover, we aimed to prospectively study the impact of a state-of-the-art PR programme on APWV and other functional vascular outcomes.

\section{Methods}

Study design and subjects

The CIRO comorbidity (CIROCO) study (approved by the local ethics and review boards (MEC 10-3-067)) was a 2-year prospective single-centre study. Patients with COPD were recruited at the start of PR at CIRO+ (Centre of Expertise for Chronic Organ Failure, Horn, the Nethrlands). Study design, inclusion and exclusion criteria and details of the assessments have been published [14]. Briefly, in addition to comprehensive pre- and post-PR clinical assessment, patient's haemodynamic status was assessed: blood pressure, pulse pressure, pulse wave analysis and APWV (SphygmoCor; AtCor Medical, Sydney, Australia). APWV was measured by recording ECG-gated carotid and femoral artery waveforms. The Sphygmocor system software assured the quality of the pulse wave measurement. A detailed screen showed $10 \mathrm{~s}$ of recorded and analysed waveforms, which can be examined to assess overall consistency of the waveforms. In addition, a detailed report helped to interpret the consistency of the waveforms during the 10-s measurement. A measurement was only retained when it met the predefined quality thresholds. After marking the exact location, measurements were repeated three times to secure reproducibility. A measurement was accepted when it was reproducible three times with minimal variation, as judged by the biomedical technologist. The retained APWV measurement was the mean of the three measurements.

Shortest distances from manubrium to the marked location on the femoral artery (via the navel) were measured. Wave transit time was calculated by the system software, using the R-wave of the simultaneously recording ECG as a reference frame. APWV was determined by dividing the distance between the two recording sites by the wave transit time. For baseline comparison, healthy never, former and current-healthy elderly smokers without airflow limitation underwent lung function tests and haemodynamic assessments as part of the ICE-AGING (Individualized COPD Evaluation in relation to AGEing) study (MEC 10-3-033).

\section{PR programme}

$\mathrm{CIRO}+$ provides a state-of-the-art interdisciplinary PR programme for patients with COPD consisting of 40 sessions, in line with the latest official American Thoracic Society and European Respiratory Society statement on PR [15]. During the baseline assessment a careful characterisation of the extrapulmonary features and comorbidities of patients with COPD were performed, which determined the application of various treatments: physical exercise training, occupational therapy, dietary counselling, psychosocial counselling, education and exacerbation management. Physical exercise training was the cornerstone of the programme, consisting of exercises to strengthen groups of muscle in the upper and lower extremities, treadmill walking and stationary cycling. All exercises were performed at moderate to high intensity to obtain an overload stimulus. Moreover, the training intensity increased during the rehabilitation period, based on dyspnoea and fatigue symptom scores. All patients underwent flexibility exercises, general physical exercise for lower and upper extremities, and daily supervised 30-min outdoor walks.

\section{Statistical analysis}

Statistics were performed using SPSS version 19.0 (SPSS Inc., Chicago, IL, USA). Results are expressed as mean $\pm S D$ or count $(\%)$. For comparison, Chi-squared tests, independent samples t-test, paired t-test or ANOVA were used where applicable. Relationships between continuous variables were analysed using simple and/or multivariate linear regression. Figure 1 was obtained using SAS version 9.1 (SAS Institute 

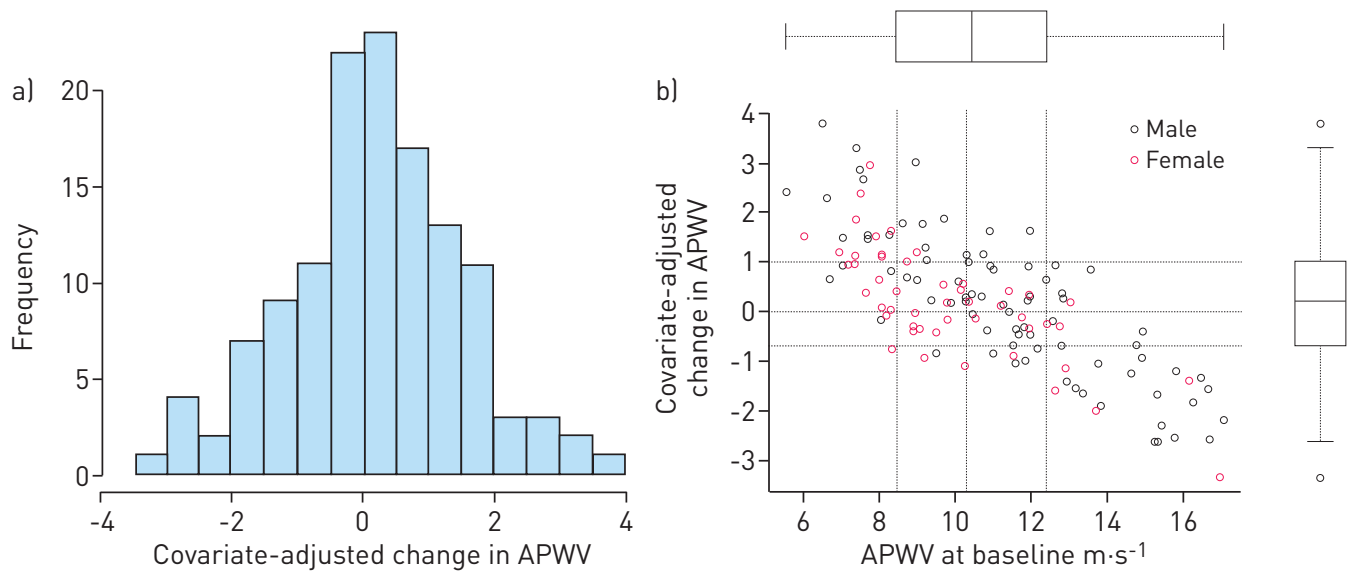

FIGURE 1 Covariate-adjusted change in aortic pulse wave velocity (APWV) after pulmonary rehabilitation (PR) in function of baseline APWV level. Change in APWV is adjusted for age, mean blood pressure, sex and body mass index. a) shows the distribution of the change in APWV after PR. b) shows the change in APWV after PR in function of the baseline APWV level for males and females. Correlation: $r=-0.77 ; \mathrm{p}<0.001$.

Inc., Cary, NC, USA). More precisely, a model was constructed for change in APWV including the covariates: sex, age, body mass index (BMI), mean blood pressure, and APWV at baseline. Only fixed effects were used, as baseline APWV was included as a covariate and only two time-points were observed. Males aged 60 years with a BMI of $25 \mathrm{~kg} \cdot \mathrm{m}^{-2}$, mean blood pressure of $100 \mathrm{mmHg}$, and a baseline APWV level of $10 \mathrm{~m} \cdot \mathrm{s}^{-1}$ were the reference group. All p-values $<0.05$ were considered statistically significant.

\section{Results}

Subjects

Of 255 prospectively recruited patients, 42 (16.5\%) were ineligible (online supplementary fig. e1). 51 (23.9\%) of the 213 eligible COPD patients were excluded because of unsuccessful APWV measurements at baseline. Patients with unsuccessful APWV measurements had a significantly higher BMI, fat-free mass index (FFMI), triglycerides, glucose, diffusing capacity of the lung for carbon monoxide (DLCO), and estimated glomerular filtration rate compared with those with successful measurements (online supplementary table e1). A total of 162 subjects with successful baseline assessment started PR. Of these, nine $(5.6 \%)$ subjects dropped out from the study before the end of the PR programme (online supplementary fig. e1). In 24 (15.7\%) subjects, APWV measurements failed following PR. These subjects did not significantly differ from subjects with two successful APWV measurements in terms of baseline characteristics and PR outcome. Therefore, 129 patients with COPD had full data before and after PR.

\section{Baseline characteristics}

On average, the study sample consisted of older patients with a substantial smoking history, moderate-tosevere COPD, and impaired diffusion capacity, but normal arterial blood gases (table 1). Almost one-third of the patients were active smokers, while $14 \%$ of the patients were on long-term oxygen therapy. Patients generally had normal BMI and FFMI. Most patients reported a necessity to stop while walking at their own pace.

About one-third of the patients had self-reported cardiovascular comorbidity. Subjects generally had a high normal blood pressure and resting heart rate. Other baseline measurements and inflammatory biomarkers are shown in table 1.

The majority of the patients used long-acting anticholinergics and/or combined inhaled corticosteroids and long-acting $\beta$-agonists (online supplementary tables e 2 and e 3 ). Moreover, $\sim 40 \%$ of the patients used one or more blood pressure lowering drugs and almost 35\% used lipid lowering drugs.

Characteristics of the healthy controls, stratified for smoking history are also shown in table 1. These healthy-control subjects are slightly younger and had slightly higher BMI and FFMI when compared with the patients with COPD. As, by definition, pulmonary function is normal in these subjects, these subjects used less antihypertensive medication and fewer anxiolytics, antidepressives, calcium supplementation, bisphosphonates or antacids when compared with the COPD patients (online supplementary table e3). 
TABLE 1 Baseline characteristics of subjects with chronic obstructive pulmonary disease (COPD) and non-COPD controls

\begin{tabular}{|c|c|c|c|}
\hline & COPD & $\begin{array}{l}\text { Never-smoking } \\
\text { controls }\end{array}$ & $\begin{array}{l}\text { Ex-smoking } \\
\text { controls }\end{array}$ \\
\hline Subjects & 162 & 65 & 102 \\
\hline \multicolumn{4}{|l|}{ Demographics } \\
\hline Age years & $63.8 \pm 6.9$ & $57.9 \pm 8.1^{*}$ & $61.4 \pm 6.7^{*, \#}$ \\
\hline Male & $97(59.9)$ & $31(47.0)^{*}$ & $47(45.6) *$ \\
\hline Active smoker & $47(29.0)$ & 0 & 0 \\
\hline Long-term oxygen therapy & $22(13.6)$ & 0 & 0 \\
\hline Smoking history pack-years & $45.9 \pm 27.3$ & $0 \pm 0$ & $15.4 \pm 14.4^{*}$ \\
\hline \multicolumn{4}{|l|}{ Body composition } \\
\hline Body mass index $\mathrm{kg} \cdot \mathrm{m}^{-2}$ & $25.0 \pm 4.1$ & $26.7 \pm 3.9^{*}$ & $27.6 \pm 3.8^{*}$ \\
\hline Fat-free mass index $\mathrm{kg} \cdot \mathrm{m}^{-2}$ & $16.6 \pm 2.1$ & $17.6 \pm 2.4^{*}$ & $17.9 \pm 2.4^{*}$ \\
\hline Bone mineral density T-score & $-1.1 \pm 1.3$ & & \\
\hline \multicolumn{4}{|l|}{ Pulmonary function } \\
\hline FEV $1 \mathrm{~L}$ & $1.40 \pm 0.55$ & $3.4 \pm 0.9 *$ & $3.3 \pm 0.9 *$ \\
\hline FEV $1 \%$ predicted & $51.4 \pm 17.4$ & $119.6 \pm 14.8^{*}$ & $119.2 \pm 17.7^{*}$ \\
\hline FEV1/FVC \% & $39.5 \pm 11.1$ & $78.0 \pm 5.0^{*}$ & $78.0 \pm 8.4^{*}$ \\
\hline DLCo $\%$ predicted & $53.8 \pm 16.7$ & $95.8 \pm 12.3^{*}$ & $91.7 \pm 17.7^{*}$ \\
\hline \multicolumn{4}{|l|}{ Blood gases } \\
\hline $\mathrm{PaCO}_{2} \mathrm{kPa}$ & $5.3 \pm 0.6$ & & \\
\hline $\mathrm{PaO}_{2} \mathrm{kPa}$ & $9.5 \pm 1.1$ & & \\
\hline Oxygen saturation \% & $94.4 \pm 7.6$ & & \\
\hline \multicolumn{4}{|l|}{ Functional outcome } \\
\hline 6MWD m & $475 \pm 108$ & & \\
\hline CWRT time s & $359 \pm 284$ & & \\
\hline Leg press weight $\mathrm{kg}$ & $101 \pm 47$ & & \\
\hline mMRC grade & $2.1 \pm 1.1$ & & \\
\hline SGRQ points & $51.6 \pm 18.4$ & & \\
\hline Charlson comorbidity index & $1.57 \pm 0.89$ & & \\
\hline Myocardial infarction & $16 \overline{(9.9)}$ & & \\
\hline Heart failure & $5(3.1)$ & & \\
\hline Peripheral arterial disease & 30 (18.5) & & \\
\hline Cerebrovascular disease & $14(8.6)$ & & \\
\hline Any cardiovascular disease & $50(30.9)$ & & \\
\hline Diabetes & $7(4.3)$ & & \\
\hline \multicolumn{4}{|l|}{ Clinical chemistry } \\
\hline Triglycerides $\mathrm{mmol} \cdot \mathrm{L}^{-1}$ & $1.5 \pm 0.7$ & & \\
\hline Low-density lipoprotein $\mathrm{mmol} \cdot \mathrm{L}^{-1}$ & $2.9 \pm 1.0$ & & \\
\hline High-density lipoprotein $\mathrm{mmol} \cdot \mathrm{L}^{-1}$ & $1.7 \pm 0.5$ & & \\
\hline Glucose $\mathrm{mmol} \cdot \mathrm{L}^{-1}$ & $5.7 \pm 0.7$ & & \\
\hline Creatinine & $87.5 \pm 22.6$ & & \\
\hline eGFR $\mathrm{mL} \cdot \mathrm{min}^{-1}$ & $75.9 \pm 21.5$ & & \\
\hline \multicolumn{4}{|l|}{ Systemic inflammatory markers } \\
\hline $\mathrm{C}$-reactive protein $\mathrm{mg} \cdot \mathrm{L}^{-1}$ & $4.6 \pm 6.1$ & & \\
\hline Interleukin-6 pg $\cdot \mathrm{mL}^{-1}$ & $3.3 \pm 4.5$ & & \\
\hline Interleukin-8 $\mathrm{pg} \cdot \mathrm{mL}^{-1}$ & $13.0 \pm 5.3$ & & \\
\hline $\mathrm{sTNFR} 1 \mathrm{pg} \cdot \mathrm{mL}^{-1}$ & $2186 \pm 771$ & & \\
\hline $\mathrm{sTNFR} 2 \mathrm{pg} \cdot \mathrm{mL}^{-1}$ & $3714 \pm 1435$ & & \\
\hline Leukocytes $10^{9}$ per $L$ & $7.5 \pm 2.0$ & & \\
\hline
\end{tabular}

Data are presented as $\mathrm{n}$, mean $\pm \mathrm{SD}$ or $\mathrm{n}(\%)$. FEV1: forced expiratory volume in $1 \mathrm{~s}$; FVC: forced vital capacity; $\mathrm{DLCO}$ : diffusing capacity of the lung for carbon monoxide; $\mathrm{PaCO}_{2}$ : arterial carbon dioxide tension; $\mathrm{PaO}_{2} ;$ arterial oxygen tension; 6MWD: 6-min walking distance; CWRT: continuous work rate test; mMRC: modified Medical Research Council; SGRQ: St George's Respiratory Questionnaire; eGFR: estimated glomerular filtration rate; STNFR: soluble tumour necrosis factor receptor. ${ }^{*}: \mathrm{p}<0.05$ in comparison with subjects with COPD; ${ }^{\#}: \mathrm{p}<0.05$ in comparison with never-smoking controls.

Haemodynamic measurement in COPD patients and healthy controls

Patients with COPD had a significantly higher APWV compared with never smoking and ex-smoking controls (table 2). Consistently, central augmentation index (normalised for a heart rate of 75 beats per 
TABLE 2 Haemodynamic measurements at baseline of subjects with chronic obstructive pulmonary disease (COPD) and controls

\begin{tabular}{|c|c|c|c|}
\hline Haemodynamic measurements & COPD & Never-smoking controls & Ex-smoking controls \\
\hline Subjects $\mathrm{n}$ & 162 & 65 & 102 \\
\hline Aortic pulse wave velocity $\mathrm{m} \cdot \mathrm{s}^{-1}$ & $10.9 \pm 2.8$ & $8.7 \pm 2.2^{*}$ & $9.0 \pm 2.9 *$ \\
\hline \multicolumn{4}{|l|}{ Peripheral $\mathrm{mmHg}$} \\
\hline Systolic pressure & $137 \pm 21$ & $141 \pm 17$ & $146 \pm 21 *$ \\
\hline Diastolic pressure & $82 \pm 10$ & $84 \pm 8$ & $85 \pm 9 *$ \\
\hline Cardiac frequency beats per min & $68 \pm 11$ & $58 \pm 8^{*}$ & $59 \pm 8 *$ \\
\hline \multicolumn{4}{|l|}{ Central pressure $\mathrm{mmHg}$} \\
\hline Systolic pressure & $129 \pm 20$ & $133 \pm 16$ & $138 \pm 21 *$ \\
\hline Diastolic pressure & $83 \pm 10$ & $85 \pm 9$ & $86 \pm 9 *$ \\
\hline Mean pressure & $102 \pm 13$ & $105 \pm 11$ & $108 \pm 13^{*}$ \\
\hline Pulse pressure & $46 \pm 15$ & $48 \pm 12$ & $52 \pm 15^{*}$ \\
\hline
\end{tabular}

Data are presented as mean+SD, unless otherwise stated. *: $p<0.05$ in comparison with subjects with COPD.

min) was higher in subjects with COPD compared with both control groups. Ex-smoking controls had a higher peripheral and central blood pressure compared with COPD patients. Although peripheral pulse pressure is higher in ex-smoking controls, central pulse pressure is higher in COPD patients. COPD patients have a significantly higher heart rate compared with both control groups (table 2).

\section{Determinants of APWV in COPD}

APWV did not correlate with systemic levels of leukocytes, C-reactive protein (CRP), IL)-6, IL-8 or sTNFR2. A weak but statistically significant correlation was found between APWV and sTNFR1. After adjusting for age, mean blood pressure, sex and BMI none of the systemic inflammatory markers were associated with APWV (table 3). Moreover, in a multivariate, backward linear-regression model, including all assessed demographics and clinical variables, only blood pressure $(\beta=0.380$, t-test $=4.515 ; \mathrm{p}<0.001)$ and age $(\beta=0.376$, t-test $=3.283 ; p=0.001)$ were independently associated with APWV. The systemic inflammatory markers, as well as DLCO, forced expiratory volume in $1 \mathrm{~s} \%$ predicted, bone mineral density T-score, BMI, lipids, blood glucose, renal function and smoking status did not explain the variance in baseline APWV in patients with COPD (online supplementary table e4).

\section{Effects of PR}

The following parameters all improved significantly when compared with baseline: 6-min walking distance (from $478 \pm 108$ to $509 \pm 102 \mathrm{~m}$ ), cycle endurance (from $371 \pm 275$ to $569 \pm 396 \mathrm{~s}$ ), muscle strength (leg press, from $103 \pm 48$ to $128 \pm 50 \mathrm{~kg}$ ), health status (St George's Respiratory Questionnaire, from $52.0 \pm 19.9$ to $48.2 \pm 18.7$ points) and dyspnoea grade (modified Medical Research Council grade $2.14 \pm 1.2$ to

TABLE 3 Simple and multivariate linear regression with aortic pulse wave velocity as the dependent variable

\begin{tabular}{|c|c|c|c|c|c|c|c|}
\hline & \multicolumn{3}{|c|}{ Simple linear regression } & \multicolumn{4}{|c|}{ Multivariate linear regression ${ }^{\#}$} \\
\hline C-reative protein $\mathrm{ng} \cdot \mathrm{mL}^{-1}$ & 0.134 & 1.584 & 0.116 & 0.098 & 1.325 & 0.187 & -6.044 \\
\hline Interleukin-6 pg $\cdot \mathrm{mL}^{-1}$ & 0.065 & 0.761 & 0.448 & 0.017 & 0.231 & 0.818 & -6.477 \\
\hline Interleukin-8 pg $\cdot \mathrm{mL}^{-1}$ & 0.101 & 1.192 & 0.235 & 0.101 & 1.357 & 0.177 & -6.165 \\
\hline Leukocytes $\times 10^{9}$ per L & 0.043 & 0.547 & 0.585 & 0.022 & 0.327 & 0.744 & -3.185 \\
\hline
\end{tabular}

sTNFR: soluble tumour necrosis factor receptor. " : adjusting for age, mean blood pressure, sex and body mass index (BMI); ": F of the model with age, mean blood pressure, sex and $\mathrm{BMI}=15.66$. 
$1.54 \pm 1.0$ points) (online supplementary table e5). BMI did not change after PR in overweight and obese patients $\left(\mathrm{n}=65,28.5 \pm 2.6\right.$ versus $\left.28.5 \pm 2.7 \mathrm{~kg} \cdot \mathrm{m}^{-2} ; \mathrm{p}=0.744\right)$. In underweight patients $(\mathrm{n}=23)$, BMI increased significantly $\left(18.7 \pm 1.5\right.$ versus $\left.19.4 \pm 1.3 \mathrm{~kg} \cdot \mathrm{m}^{-2} ; \mathrm{p}<0.001\right)$. The systemic inflammatory markers, lipids, fasting glucose and leukocytes did not change following PR (online supplementary table e6).

APWV, central or peripheral blood pressure, or augmentation index did not change following PR, while peripheral- and central-pulse pressure increased (fig. 2). A statistically significant, but most probably clinically irrelevant, reduction in cardiac frequency was seen (table 4). Also, after stratification of the study sample in different relevant subgroups, no changes in APWV were noticed after PR (table 5).

The change in APWV following PR was negatively correlated $(r=-0.77, \mathrm{p}<0.001)$ with the level of APWV at baseline, after adjustment for baseline age, average blood pressure, sex and BMI in a linear fixed effects model (fig. 1). Interestingly, subjects with a low baseline APWV $\left(<8 \mathrm{~m} \cdot \mathrm{s}^{-1}\right.$ (25th percentile of the study sample)) whose APWV values increased by at least $0.5 \mathrm{~m} \cdot \mathrm{s}^{-1}$ after PR $(\mathrm{n}=19)$ and patients with a high baseline APWV $\left(12.5 \mathrm{~m} \cdot \mathrm{s}^{-1}\right.$ (75th percentile of the study sample)) whose APWV values decreased at least $0.5 \mathrm{~m} \cdot \mathrm{s}^{-1}(\mathrm{n}=15)$ were not different with respect to baseline clinical characteristics, systemic inflammation or PR outcome.

\section{Discussion}

The main findings of this study are as follows. First, central arterial stiffness is increased in a large sample of subjects with COPD compared with healthy controls, and variance in arterial stiffness is partially determined by age and resting blood pressure. Secondly, markers of systemic inflammation do not explain the variance in arterial stiffness in COPD. Thirdly, although patients with COPD improved on conventional rehabilitation outcomes, arterial stiffness generally does not change following PR.

\section{Arterial stiffness in COPD}

Cardiovascular disease is common in patients with COPD and affects prognosis [16]. Moreover, patients with COPD have stiffer arteries compared with healthy control subjects [7, 17]. The current study corroborates these findings. Surprisingly, blood pressure and pulse pressure were higher in ex-smoking controls. This is probably due to less use of antihypertensive therapy in healthy subjects.

Arterial stiffness has been proposed as a mechanistic link between COPD and cardiovascular disease [18]. Increasing arterial stiffness alters arterial pressure and flow dynamics and impacts cardiac performance and coronary perfusion with consequent cardiovascular disease [19]. Arterial stiffness is thought to be the result of a remodelling process with elastin fragmentation and collagen replacement in the extracellular matrix [19]. A systemic susceptibility to lung, skin and arterial degradation of elastin and extracellular matrix remodelling has been suggested in patients with an emphysematous phenotype of COPD [20]. Indeed, MCALLISTER et al. [21] showed a positive correlation between arterial stiffness and high-resolution computed tomography (HRCT)-quantified emphysema in 77 COPD patients. HRCT was not available in

FIGURE 2 Data plot for aortic pulse wave velocity (APWV) in each patient before and after pulmonary rehabilitation. Circles and solid line represent the mean.

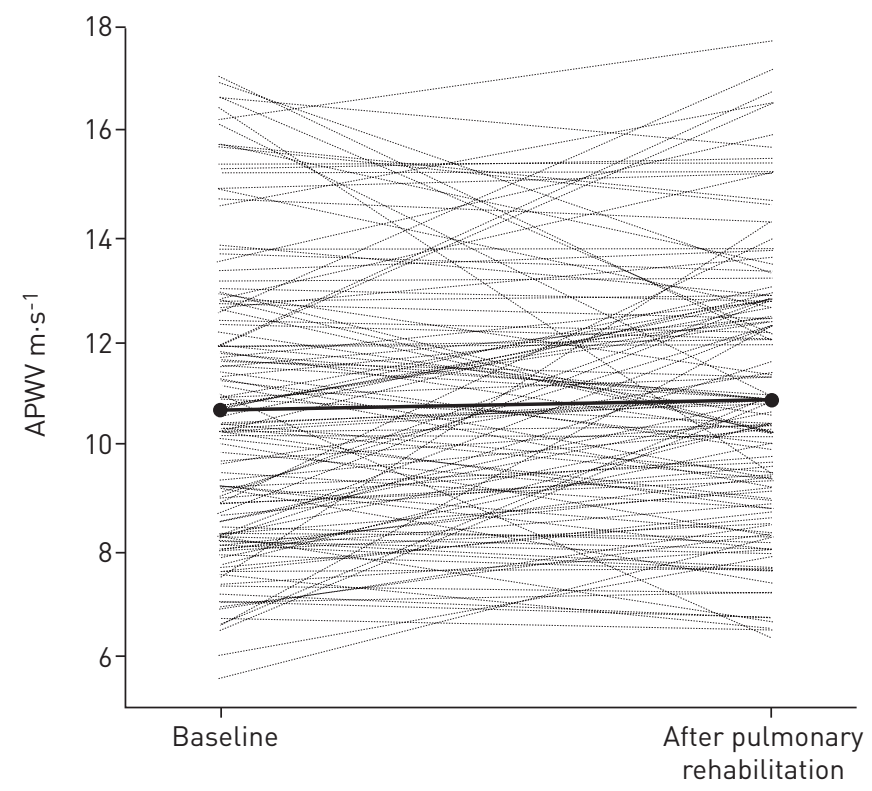




\begin{tabular}{|c|c|c|c|}
\hline Haemodymanic measurement & Baseline & After PR & $\mathrm{p}$-value \\
\hline Aortic pulse wave velocity $\mathrm{m} \cdot \mathrm{s}^{-1}$ & $10.7 \pm 2.7$ & $10.9 \pm 2.5$ & 0.339 \\
\hline Central augmentation index \% & $30.8 \pm 8.1$ & $30.2 \pm 8.1$ & 0.129 \\
\hline \multicolumn{4}{|l|}{ Peripheral pressure mmHg } \\
\hline Systolic pressure & $135 \pm 19$ & $137 \pm 19$ & 0.064 \\
\hline Diastolic pressure & $81 \pm 9$ & $81 \pm 9$ & 0.377 \\
\hline Mean pressure & $101 \pm 12$ & $101 \pm 12$ & 0.427 \\
\hline Pulse pressure & $54 \pm 15$ & $57 \pm 15$ & 0.004 \\
\hline Cardiac frequency beats per $\min$ & $68 \pm 11$ & $67 \pm 11$ & 0.032 \\
\hline \multicolumn{4}{|l|}{ Central pressure $\mathrm{mmHg}$} \\
\hline Systolic pressure & $127 \pm 18$ & $129 \pm 19$ & 0.061 \\
\hline Diastolic pressure & $82 \pm 9$ & $82 \pm 9$ & 0.386 \\
\hline Mean pressure & $101 \pm 12$ & $101 \pm 12$ & 0.428 \\
\hline Pulse pressure & $44 \pm 14$ & $47 \pm 14$ & 0.003 \\
\hline
\end{tabular}

Data are presented as mean $\pm S D$, unless otherwise stated. ${ }^{*}: n=129$.

our study, but DLCO (as another surrogate for pulmonary emphysema) was not associated with APWV. Although DLCO and computed tomography-quantified emphysema have shown to be only moderately correlated [22], the discrepancy in these surrogates for pulmonary emphysema is intriguing as the populations in both studies are quite similar regarding demographics and clinical characteristics.

Also, vascular calcification may have a role in arterial stiffness in COPD, as it is inversely associated with bone mineral density in the general population [23], and osteoporosis is highly prevalent in COPD. Indeed, SABIT et al. [7] showed the highest arterial stiffness in nine emphysematous patients with osteoporosis at the hip, compared with 62 emphysematous subjects without osteoporosis. However, these differences were not found for the 13 subjects with osteoporosis of the spine and total T-score was not reported in that study.

In contrast, in the present study, total body bone mineral density $\mathrm{T}$-score did not independently predict APWV, suggesting that this association might be more complex than assumed at present. Moreover, multivariate analysis indicated only increasing age and higher blood pressure to be independent predictors of increased arterial stiffness. This is comparable to the general population and multiple other patients groups, as was recently systematically reviewed [24].

\section{Arterial stiffness and systemic inflammation}

Increased levels of systemic inflammatory markers (leukocytes, CRP, tumour necrosis factor- $\alpha$, IL- 6 and IL-8) have been reported in COPD [25], and several of these have been associated with subclinical

\section{TABLE 5 Difference in aortic pulse wave velocity (APWV) after pulmonary rehabilitation (PR) in different subgroups}

\begin{tabular}{|c|c|c|c|c|}
\hline Overweight and obese & 65 & $10.9 \pm 2.7$ & $11.2 \pm 2.3$ & 0.315 \\
\hline No blood pressure lowering medication & 79 & $10.5 \pm 2.6$ & $10.7 \pm 2.4$ & 0.383 \\
\hline No lipid lowering drugs & 92 & $10.5 \pm 2.7$ & $10.7 \pm 2.4$ & 0.209 \\
\hline No cardiovascular medical history according to the $\mathrm{CCl}$ & 60 & $10.3 \pm 2.6$ & $10.6 \pm 2.5$ & 0.232 \\
\hline Ex-smokers & 94 & $10.8 \pm 2.7$ & $11.1 \pm 2.5$ & 0.151 \\
\hline Male & 80 & $11.2 \pm 2.8$ & $11.5 \pm 2.7$ & 0.520 \\
\hline Female & 49 & $9.8 \pm 2.4$ & $10.0 \pm 1.8$ & 0.417 \\
\hline Improvement of $>50 \mathrm{~m}$ in $6 \mathrm{MWD}$ and $>4$ points on SGRQ & 25 & $10.4 \pm 2.7$ & $10.4 \pm 1.9$ & 0.954 \\
\hline Normal blood pressure $<140 / 90 \mathrm{mmHg}$ & 79 & $10.0 \pm 2.5$ & $10.2 \pm 2.4$ & 0.395 \\
\hline Hypertensive $>140 / 90 \mathrm{mmHg}$ & 49 & $11.8 \pm 2.7$ & $12.0 \pm 2.3$ & 0.585 \\
\hline
\end{tabular}

Data are presented as mean \pm SD, unless otherwise stated. CCI: Charlson comorbidity index; 6MWD: 6-min walking distance; SGRQ: St George's Respiratory Questionnaire. 
atherosclerosis [26] and ischaemic heart disease [27]. Similar to SABIT et al. [7], we found a univariate association between APWV and sTNFR1, but we could not confirm the association with IL-6. However, IL-6 was reported to be significantly associated with APWV in a multivariate regression; although this needs to be interpreted with caution, as the control subjects were also included in the regression analysis. In our study, the multivariate model only included patients with COPD.

Systemic inflammation is thought to accelerate and stimulate the vascular extracellular matrix remodelling process of elastin fragmentation and collagen deposition, resulting in arterial stiffness [19]. However, evidence for a causal relationship between low-grade systemic inflammation and a high incidence of cardiovascular disease in COPD is lacking. In addition, studies showed comparable circulating levels of inflammatory biomarkers in COPD patients with and without cardiovascular disease [28]. Furthermore, it was recently shown that systemic inflammation does not affect all patients with COPD. Only 16\% of patients in the Evaluation of COPD Longitudinally to Identify Predictive Surrogate Endpoints (ECLIPSE) cohort had long-term systemic inflammation, while one-third of the patients in this cohort did not have systemic inflammation at all during a 1-year follow-up [29]. Interestingly, increasing age and having an overweight to obese BMI were independent risk factors for systemic inflammation in the ECLIPSE study, whereas self-reported cardiovascular disease was not. Also, in the present study, systemic inflammatory markers were not independent from traditional cardiovascular risk factors associated with arterial stiffness.

\section{Arterial stiffness and PR}

Endurance-trained athletes have higher large-artery compliance than do their sedentary counterparts [30], and training improves arterial stiffness in healthy young [31] and elderly subjects [32, 33]. However, the effects of exercise training on arterial stiffness in elderly patient populations are contradictory [34-38]. This issue is further complicated by the heterogeneity among studies in modality, frequency and duration of exercise training, and in the assessment method for arterial stiffness.

VIVODTZEV et al. [12] were the first to show significant improvements in brachial pulse wave velocity in 10 patients with COPD who underwent a 4-week aerobic endurance training programme. Peripheral (brachial) muscular arteries are more susceptible to modification by exercise training than central (aortic) elastic arteries [39]. Indeed aortic stiffening is more attributable to elastin degradation and is largely irreversible [40]. Moreover, APWV is the gold standard for measurement of arterial stiffness as it predicts cardiovascular events and mortality in different populations. GALE et al. [13] showed a small, but significant, reduction in APWV in an observational study of 32 patients with COPD following an outpatient-based thrice-weekly PR programme including endurance training and resistance training. However, the change in APWV following PR was highly variable. We confirmed the variability of the change in APWV after PR but we were not able to confirm a significant reduction in APWV; even though the number of subjects, the number of PR sessions and baseline APWV were higher in the present study and subjects generally improved on classical rehabilitation outcomes.

There are several possible explanations for this lack of response. Mechanisms underlying arterial stiffness with age, such as elastin degradation, are likely to be enhanced and accelerated in patients with COPD and are unlikely to be influenced by a PR programme of limited duration.

Furthermore, the possible effects of exercise training on arterial stiffness might be influenced by a patient's concurrent pharmacological treatment. Cardiovascular medication [41] and combination therapy of inhaled corticosteroids and long-acting $\beta$-agonists (inhaled corticosteroids or long-acting $\beta$-agonists) [42] may decrease arterial stiffness and the majority of subjects use these medications chronically. However, nonsignificant changes in APWV were observed in patients who were not known to have cardiovascular disease or were untreated with cardiovascular medication. Earlier studies suggested that sex [43], smoking status, body composition and systemic hypertension could play a role in the effect of exercise on arterial stiffness, but none were found to significantly influence changes in arterial stiffness following PR.

The exercise modalities may explain the lack of decrease in arterial stiffness. In marked contrast to the beneficial effect of aerobic training in healthy younger individuals, it was shown that resistance training increases arterial stiffness in young healthy males [44, 45]. Similar opposite effects of endurance and resistance training on arterial stiffness were seen in a study in hypertensive patients [46]. In patients with type 2 diabetes, an increased APWV was seen after 2 years of endurance and resistance training [39].

Thus, resistance training may have outweighed the effects of endurance training on arterial stiffness. The increase in pulse pressure, which has been considered to be a key feature of arterial stiffening, may be an outcome related to resistance training. Importantly, short-term progressive resistance exercise can lead to appreciable increases in muscle strength for people with COPD, which may carry over to the performance of some daily activities [47]. Indeed, the combination of constant-load/interval and strength training is 
recommended in state-of-the-art PR to treat peripheral muscle dysfunction in chronic respiratory disease, because it results in combined improvements in exercise capacity and muscle strength. Nevertheless, it would be interesting to compare the effect of endurance versus resistance training on APWV in patients with COPD.

Baseline arterial stiffness correlated very well with the change in arterial stiffness after PR, even after adjustment for possible confounders, such as age, blood pressure, sex and BMI. It is unclear whether and to what extent this correlation could be explained by statistical bias (regression to the mean). Still, the finding is interesting and worth discussing, as the correlation was highly significant. Moreover, in a study evaluating the effect of fluticasone propionate/salmeterol on arterial stiffness in patients with COPD, a decrease in APWV was only seen in patients with a baseline APWV belonging to the highest baseline tertile of the study sample [42]. However, it is noticeable that patients at both extremes (decreasers with high baseline stiffness versus increasers with low baseline stiffness) did not differ in terms of disease severity, health status, age, BMI or systemic inflammation. This confirms that arterial stiffness and its change cannot be predicted by these clinical outcomes. It is of note that we did not identify other studies that evaluated differences in characteristics of responders and nonresponders in terms of arterial stiffness and exercise programmes.

A limitation of this study is the lack of a nonexercising COPD control group. Although, it seems reasonable to speculate that APWV does not change during 8 weeks of usual care, a nonexercising COPD control group would have been desirable. A second limitation is the absence of a direct reproducibility analysis at the baseline of the study. Nevertheless, we are confident in the quality and reproducibility of the data in our study, given the strict quality control criteria (see Methods section). Moreover, two recent studies specifically addressed reproducibility of APWV measurements in COPD and found that this was highly reproducible and not affected by lung hyperinflation $[48,49]$.

A third limitation is that HRCT would have been preferable to evaluate emphysema against arterial stiffness. Finally, heterogeneity among the included COPD patients may have blunted any effects of PR on arterial stiffness. However, phenotyping of patients was extensive and the large number of patients in this study allowed for post-stratification.

In conclusion, central arterial stiffness is increased in subjects with COPD and determined by blood pressure and age. Systemic inflammation does not explain the variance in APWV. Furthermore, although subjects improved on classic rehabilitation outcomes, arterial stiffness is resistant to modification through a state-of-the-art PR programme in patients with COPD in general and in different subgroups. Nevertheless, baseline arterial stiffness did strongly predict the change in stiffness after PR in individual patients. Ultimately, this is a negative study that conflicts with the conventional knowledge that arterial stiffness may be attributed to systemic inflammation and may be a modifiable disease-specific cardiovascular risk factor in COPD. At the same time, this is the largest study performed in COPD in this field.

\section{References}

Spruit MA, Pennings HJ, Janssen PP, et al. Extra-pulmonary features in COPD patients entering rehabilitation after stratification for MRC dyspnea grade. Respir Med 2007; 101: 2454-2463.

Huiart L, Ernst P, Suissa S. Cardiovascular morbidity and mortality in COPD. Chest 2005; 128: 2640-2646.

Curkendall SM, DeLuise C, Jones JK, et al. Cardiovascular disease in patients with chronic obstructive pulmonary disease, Saskatchewan Canada cardiovascular disease in COPD patients. Ann Epidemiol 2006; 16: 63-70.

Barnes PJ, Celli BR. Systemic manifestations and comorbidities of COPD. Eur Respir J 2009; 33: 1165-1185.

Mansia G, De Backer G, Dominiczak A, et al. 2007 ESH-ESC Guidelines for the management of arterial hypertension: the task force for the management of arterial hypertension of the European Society of Hypertension (ESH) and of the European Society of Cardiology (ESC). Blood Press 2007; 16: 135-232.

6 Cavalcante JL, Lima JA, Redheuil A, et al. Aortic stiffness: current understanding and future directions. J Am Coll Cardiol 2011; 57: 1511-1522.

7 Sabit R, Bolton CE, Edwards PH, et al. Arterial stiffness and osteoporosis in chronic obstructive pulmonary disease. Am J Respir Crit Care Med 2007; 175: 1259-1265.

8 Maclay JD, McAllister DA, Mills NL, et al. Vascular dysfunction in chronic obstructive pulmonary disease. Am J Respir Crit Care Med 2009; 180: 513-520.

9 Yasmin, McEniery CM, Wallace S, et al. C-reactive protein is associated with arterial stiffness in apparently healthy individuals. Arterioscler Thromb Vasc Biol 2004; 24: 969-974.

10 Kocyigit I, Kaya MG, Orscelik O, et al. Early arterial stiffness and inflammatory bio-markers in normotensive polycystic kidney disease patients. Am J Nephrol 2012; 36: 11-18.

11 Yiu KH, Yeung CK, Chan HT, et al. Increased arterial stiffness in patients with psoriasis is associated with active systemic inflammation. Br J Dermatol 2011; 164: 514-520.

12 Vivodtzev I, Minet C, Wuyam B, et al. Significant improvement in arterial stiffness after endurance training in patients with COPD. Chest 2010; 137: 585-592.

13 Gale NS, Duckers JM, Enright S, et al. Does pulmonary rehabilitation address cardiovascular risk factors in patients with COPD? BMC Pulm Med 2011; 11: 20.

14 Vanfleteren LE, Spruit MA, Groenen M, et al. Clusters of comorbidities based on validated objective measurements and systemic inflammation in patients with chronic obstructive pulmonary disease. Am J Respir Crit Care Med 2013; 187: 728-735. 
15 Spruit MA, Singh SJ, Garvey C, et al. An official American Thoracic Society/European Respiratory Society statement: key concepts and advances in pulmonary rehabilitation. Am J Respir Crit Care Med 2013; 188: e13-e64.

16 Divo M, Cote C, de Torres JP, et al. Comorbidities and risk of mortality in patients with chronic obstructive pulmonary disease. Am J Respir Crit Care Med 2012; 186: 155-161.

17 Maclay JD, McAllister DA, Macnee W. Cardiovascular risk in chronic obstructive pulmonary disease. Respirology 2007; 12: 634-641.

18 Macnee W, Maclay J, McAllister D. Cardiovascular injury and repair in chronic obstructive pulmonary disease. Proc Am Thorac Soc 2008; 5: 824-833.

19 Zieman SJ, Melenovsky V, Kass DA. Mechanisms, pathophysiology, and therapy of arterial stiffness. Arterioscler Thromb Vasc Biol 2005; 25: 932-943.

20 Maclay JD, McAllister DA, Rabinovich R, et al. Systemic elastin degradation in chronic obstructive pulmonary disease. Thorax 2012; 67: 606-612.

21 McAllister DA, Maclay JD, Mills NL, et al. Arterial stiffness is independently associated with emphysema severity in patients with chronic obstructive pulmonary disease. Am J Respir Crit Care Med 2007; 176: 1208-1214.

22 Lamers RJ, Thelissen GR, Kessels AG, et al. Chronic obstructive pulmonary disease: evaluation with spirometrically controlled CT lung densitometry. Radiology 1994; 193: 109-113.

23 Schulz E, Arfai K, Liu X, et al. Aortic calcification and the risk of osteoporosis and fractures. J Clin Endocrinol Metab 2004; 89: 4246-4253.

24 Cecelja M, Chowienczyk P. Dissociation of aortic pulse wave velocity with risk factors for cardiovascular disease other than hypertension: a systematic review. Hypertension 2009; 54: 1328-1336.

25 Gan WQ, Man SF, Senthilselvan A, et al. Association between chronic obstructive pulmonary disease and systemic inflammation: a systematic review and a meta-analysis. Thorax 2004; 59: 574-580.

26 Iwamoto $\mathrm{H}$, Yokoyama $\mathrm{A}$, Kitahara $\mathrm{Y}$, et al. Airflow limitation in smokers is associated with subclinical atherosclerosis. Am J Respir Crit Care Med 2009; 179: 35-40.

27 Sin DD, Man SF. Why are patients with chronic obstructive pulmonary disease at increased risk of cardiovascular diseases? The potential role of systemic inflammation in chronic obstructive pulmonary disease. Circulation 2003; 107: 1514-1519.

28 Mills NL, Miller JJ, Anand A, et al. Increased arterial stiffness in patients with chronic obstructive pulmonary disease: a mechanism for increased cardiovascular risk. Thorax 2008; 63: 306-311.

29 Agusti A, Edwards LD, Rennard SI, et al. Persistent systemic inflammation is associated with poor clinical outcomes in COPD: a novel phenotype. PloS one 2012; 7: e37483.

30 Vaitkevicius PV, Fleg JL, Engel JH, et al. Effects of age and aerobic capacity on arterial stiffness in healthy adults. Circulation 1993; 88: 1456-1462.

31 Currie KD, Thomas SG, Goodman JM. Effects of short-term endurance exercise training on vascular function in young males. Eur J Appl Physiol 2009; 107: 211-218.

32 Fujimoto N, Prasad A, Hastings JL, et al. Cardiovascular effects of 1 year of progressive and vigorous exercise training in previously sedentary individuals older than 65 years of age. Circulation 2010; 122: 1797-1805.

33 Vogel T, Leprêtre PM, Brechat PH, et al. Effect of a short-term intermittent exercise-training programme on the pulse wave velocity and arterial pressure: a prospective study among 71 healthy older subjects. Int J Clin Pract 2013; 67: 420-426.

34 Oliveira NL, Ribeiro F, Alves AJ, et al. The effects of exercise training on arterial stiffness in coronary artery disease patients: a state-of-the-art review. Clin Physiol Funct Imaging 2013 [In press DOI: 10.1111/cpf.12093].

35 Kitzman DW, Brubaker PH, Herrington DM, et al. Effect of endurance exercise training on endothelial function and arterial stiffness in older patients with heart failure and preserved ejection fraction: a randomized, controlled, single-blind trial. J Am Coll Cardiol 2013; 62: 584-592.

36 Dobrosielski DA, Gibbs BB, Ouyang P, et al. Effect of exercise on blood pressure in type 2 diabetes: a randomized controlled trial. J Gen Intern Med 2012; 27: 1453-1459.

37 Croymans DM, Krell SL, Oh CS, et al. Effects of resistance training on central blood pressure in obese young men. J Hum Hypertens 2014; 28: 157-164.

38 Mihaescu A, Avram C, Bob F, et al. Benefits of exercise training during hemodialysis sessions: a prospective cohort study. Nephron Clin Pract 2013; 124: 72-78.

39 Loimaala A, Groundstroem K, Rinne M, et al. Effect of long-term endurance and strength training on metabolic control and arterial elasticity in patients with type 2 diabetes mellitus. Am J Cardiol 2009; 103: 972-977.

40 O’Rourke MF, Hashimoto J. Arterial stiffness: a modifiable cardiovascular risk factor? J Cardiopulm Rehabil Prev 2008; 28: 225-237.

41 Duprez DA. Is vascular stiffness a target for therapy? Cardiovasc Drugs Ther 2010; 24: 305-310.

42 Dransfield MT, Cockcroft JR, Townsend RR, et al. Effect of fluticasone propionate/salmeterol on arterial stiffness in patients with COPD. Respir Med 2011; 105: 1322-1330.

43 Collier SR. Sex differences in the effects of aerobic and anaerobic exercise on blood pressure and arterial stiffness. Gend Med 2008; 5: 115-123.

44 Miyachi M, Kawano H, Sugawara J, et al. Unfavorable effects of resistance training on central arterial compliance: a randomized intervention study. Circulation 2004; 110: 2858-2863.

45 Bertovic DA, Waddell TK, Gatzka CD, et al. Muscular strength training is associated with low arterial compliance and high pulse pressure. Hypertension 1999; 33: 1385-1391.

46 Collier SR, Kanaley JA, Carhart R Jr, et al. Effect of 4 weeks of aerobic or resistance exercise training on arterial stiffness, blood flow and blood pressure in pre- and stage-1 hypertensives. J Hum Hypertens 2008; 22: 678-686.

47 O'Shea SD, Taylor NF, Paratz JD. Progressive resistance exercise improves muscle strength and may improve elements of performance of daily activities for people with COPD: a systematic review. Chest 2009; 136: 1269-1283.

48 Stone IS, John L, Petersen SE, et al. Reproducibility of arterial stiffness and wave reflections in chronic obstructive pulmonary disease: the contribution of lung hyperinflation and a comparison of techniques. Respir Med 2013; 107: $1700-1708$

49 Vivodtzev I, Minet C, Tamisier R, et al. Arterial stiffness by pulse wave velocity in COPD: reliability and reproducibility. Eur Respir J 2013; 42: 1140-1142. 